This is a postprint version of:

Morillo, F. \& Efrain-Garcia, P. (2015). A bibliometric analysis of Technology Centres.

Scientometrics, 104(3), 685-713.

The final publication is available at Springer via http://dx.doi.org/10.1007/s11192-015-1631-5

\title{
A bibliometric analysis of Technology Centres
}

\author{
Fernanda Morillo $(1,2)$ \& Preiddy Efrain-Garcia (1)
}

(1) Centre for Human and Social Sciences (CCHS), Spanish National Research Council (CSIC), Albasanz 26-28, 28037 Madrid, Spain.

(2) Corresponding author.

E-mail addresses: fernanda.morillo@cchs.csic.es \& preiddy@gmail.com

\begin{abstract}
Technology Centres (TCS) are non-profit organisations created to contribute to the improvement of the productive sector, providing RTD support, especially for small and medium-sized enterprises (SMEs). Given TCs' main function, most authors present an industrial perspective of their performance. However, the bibliometric techniques can offer not only an overview of these centres, but also additional information about their features: the evolution of their publications, the degree of national and international collaboration, the Spanish institutional sectors and the main disciplines involved, the regional differences and their connections. In this article, Spanish TCs' documents downloaded from the Web of Science (2008-2012) are analysed, along with other indicators that can characterise these centres. The results show that national collaboration is important for TCs and even more when those links are local. This is in line with that stated by other authors, considering that geographical proximity is essential for knowledge transfer. Regarding the Spanish institutional sectors, the strongest relations are established with universities. For their part, firms have low participation in publications, although they show an upward trend over the years. Nevertheless, TCs' documents are mainly issued on industrial related topics, in agreement with their primary mission as promoters of firms' innovation. Finally, as expected, differences between regions' performance are seen, explained in part by disparities between regional systems. Notwithstanding, top producers establish connections with regions without TCs, mainly collaborating in documents related to engineering, medicine and environmental topics.
\end{abstract}


This is a postprint version of:

Morillo, F. \& Efrain-Garcia, P. (2015). A bibliometric analysis of Technology Centres.

Scientometrics, 104(3), 685-713.

The final publication is available at Springer via http://dx.doi.org/10.1007/s11192-015-1631-5

\section{Keywords}

Spanish Technology Centres; Scientific publications; Collaboration; Regional differences; Performance evaluation; Statistical Analyses

\section{Introduction}

Technology Centres (TCs) are non-profit organisations created to contribute to the overall benefit of society and to the improvement of enterprises' competitiveness ${ }^{1}$. They give an effective RTD support, specifically aimed at the productive sector, chiefly SMEs, but also collaborating with public authorities in the performance of technological innovation related activities $^{2}$. TCs were originally based on the association of companies in a particular sector, although in some cases they were linked to a university from the beginning, or connected to the public sector (especially the regional one) (Giner and Santa María 2000; Barge-Gil and Modrego 2011). In a business environment where there is a high proportion of SMEs, TCs reach a broad group of firms and are the only ones who can offer the services and technical resources required to improve their innovative capacity. These organisations can build bridges between private needs and the creation of scientific knowledge of public bodies. TCs, being intermediary institutions with extensive contacts, provide specific knowledge of great value to companies (Barge-Gil and Modrego-Rico 2008).

Although their mission is closely associated to the business environment, they were often funded by a public-private joint scheme and regional governments had an important role in driving their development. However, there are large regional differences among TCs. For Valencia, each centre works mostly in one sector, oriented towards established industry, with a high proportion of SMEs and various locations, because proximity is crucial to ensure delivery service. On the contrary, in the Basque Country, TCs work in several sectors. Alongside the Basque Country, Valencia was the first to consider TCs as a key element for technology transfer and innovation in the regional business fabric. Public promotion is basic and explains the TCs' results in some regions, although they had to adapt and change their plans. In fact, in the case of the Basque Country, the regional budget constraints meant that

1

http://www.idi.mineco.gob.es/portal/site/MICINN/menuitem.7eeac5cd345b4f34f09dfd1001432ea0/?vgnextoi $\mathrm{d}=967227 \mathrm{bba0d90210VgnVCM1000001034e20aRCRD}$. Accessed 28 May 2015.

${ }^{2}$ http://www.fedit.com/Paginas/CT Presentacion.aspx. Accessed 28 May 2015. 
This is a postprint version of:

Morillo, F. \& Efrain-Garcia, P. (2015). A bibliometric analysis of Technology Centres.

Scientometrics, 104(3), 685-713.

The final publication is available at Springer via http://dx.doi.org/10.1007/s11192-015-1631-5

TCs adopted new strategies for their survival, as in the case of Tecnalia. TCs play a key role in innovation policies, but it should be borne in mind that financial incentives and rules are needed to complement them (Giner and Santa María 2000; Mas-Verdú 2007).

At the level of the country, within the last Spanish RTD Plan, a specific sub-programme of institutional strengthening is envisaged to encourage the participation of TCs. It helps them to improve their chances of obtaining Community funding under Horizon 2020. This is particularly important, in view of the limited success of innovative research transfer towards the market. In the international context, TCs are sometimes referred to as Research and Technology Organisations. The European Association of Research and Technology Organisations (EARTO) gathers some of these centres, from different countries ${ }^{3}$ and there are various studies that analyse the characteristics or performance of several of these organisations outside Spain (see, for example, Giner and Santa María 2000; Mas-Verdú 2007; Schramm et al. 2011; Ahlqvist et al., 2012).

In Spain, most authors offer an industrial vision of the TCs' performance, because their main function is to contribute to improving the competitiveness of enterprises through RTD. Some studies measure TCs' results and their fulfilment of the purpose for which they were created. For instance, Baviera-Puig et al. (2012) analyse the distribution of firms connected to a TC (as exemplified by a specialised organisation in the food industry) and stress the importance of geographical proximity for knowledge transfer. This centre is mainly related to nearby businesses, but also with others more distant, since highways, facilitating interconnection, conveniently connect each other. Other studies mainly focus on the types of activities TCs perform, their services, fund raising, organisation and relationships with the public and private sector. Modrego-Rico et al. (2005) develop indicators to measure their performance considering all these factors and producing a TCs' taxonomy, in which there are interregional differences in their specialisation. Moreover, some authors (e.g. Barge-Gil and Modrego-Rico 2008) evaluate the TCs' efforts in helping to reduce market failures. They conclude that overall there is a positive outcome, because these centres give invaluable technological services (mainly to SMEs), with an increase in R\&D investment. Finally, they point out that a key element, which improves outcomes, is cooperation with universities and firms.

\footnotetext{
${ }^{3}$ http://www.earto.eu/about-earto/list-of-members.html. Accessed 28 May 2015.
} 
This is a postprint version of:

Morillo, F. \& Efrain-Garcia, P. (2015). A bibliometric analysis of Technology Centres.

Scientometrics, 104(3), 685-713.

The final publication is available at Springer via http://dx.doi.org/10.1007/s11192-015-1631-5

\section{$\underline{\text { Objectives }}$}

This article presents a different approach applied to the study of TCs, which offers not only an overview of these centres, but also additional information about their features. The methodology is based on a bibliometric analysis of journal's publications produced by the Spanish TCs, using the Web of Science (WoS). This study provides a broader framework for understanding the role of these centres as promoters of firms' competitiveness. However, the degree to which TCs' publications reflect firms' performance is beyond the scope of this text.

The paper starts with an outline of TCs' scientific publications, examining the evolution of their documents. Then it continues with the degree of collaboration with other institutions (national or international), the Spanish institutional sectors and the scientific disciplines represented in publications, ending with the regional distribution and their connections. In particular, based on the above mentioned, the following hypotheses are formulated and tested in the present study:

1. TCS are highly connected with national organisations and mainly with those from the university sector.

In previous works, it has been indicated the importance of geographical proximity (Baviera-Puig et al. 2012) and the connections with the public sector or even with a particular university (see, for example, Giner and Santa María 2000). Therefore, it is estimated that there will be a high percentage of national collaboration and, in particular, of university cooperation.

2. TCS' performance is influenced by differences between regions, explained in part by disparities between regional systems.

As stated in other articles, it is anticipated that there will be regional differences, due in part to technological strategies followed by regions (see, for example, Giner and Santa María 2000).

To provide a robust response to the second hypothesis, statistical analysis is used. The next section of this work describes in detail the data, methodological approach and measures employed. Results offer the descriptive and statistical tests and discussion and conclusions explain these results in context, giving possible directions in future research. 
This is a postprint version of:

Morillo, F. \& Efrain-Garcia, P. (2015). A bibliometric analysis of Technology Centres.

Scientometrics, 104(3), 685-713.

The final publication is available at Springer via http://dx.doi.org/10.1007/s11192-015-1631-5

\section{Materials and methodology}

All the Spanish documents were downloaded from WoS, years 2008-2012, and those publications signed by TCs at least once were selected. In this study, 75 TCs (Appendix Table 5) were gathered from different sources (through web pages information and/or through email answers). These centres were identified, in WoS documents, and the Spanish institutional sectors with which they collaborate, using automatic applications that analyse addresses and assign optional codes from various master lists (Morillo et al. 2013a; Morillo et al. 2013b).

In addition, to have a more comprehensive view of the regional typologies, some measures obtained from the Spanish Statistical Office (INE) ${ }^{4}$ are used: R\&D expenditure (percentage of GDP), firms' innovation intensity (innovative activities expenditure / turnover x100), number of firms with innovative activities per 1000 inhabitants and R\&D university personnel per 1000 inhabitants. Besides, as most nationwide TCS are integrated in a register of MINECO (the Spanish Ministry of Economy and Competitiveness) ${ }^{5}$, the sectoral classification of this register was used. Those TCs included in the register, and studied in this work (i.e. 46 centres, Appendix Table 5), were assigned to their respective technological and/or industrial sectors, as well as to their documents' categories (WoS), in order to compare both classifications.

Furthermore, a nonparametric statistical analysis was carried out using SPSS (IBM Corp. 2013). In particular, Spearman rho coefficient was calculated to assess the association between the regional variables, considering two significance levels (0.01 and 0.05). In addition, a k-means cluster analysis was made, which aimed to determine three groups of regions (of high, medium and low performance). Finally, to study the detail of the national collaboration, connections between organisations from the different Spanish regions (TCs or not) are displayed in a network generated with Pajek (Batagelj and Mrvar 2013).

\footnotetext{
${ }_{5}^{4}$ http://www.ine.es/en/welcome.shtml. Accessed 28 May 2015.

http://www.idi.mineco.gob.es/portal/site/MICINN/menuitem.7eeac5cd345b4f34f09dfd1001432ea0/?vgnextoi d=967227bba0d90210VgnVCM1000001034e20aRCRD. Accessed 28 May 2015.
} 
This is a postprint version of:

Morillo, F. \& Efrain-Garcia, P. (2015). A bibliometric analysis of Technology Centres.

Scientometrics, 104(3), 685-713.

The final publication is available at Springer via http://dx.doi.org/10.1007/s11192-015-1631-5

\section{Results}

The general results showed that TCs produced 5,068 documents and 4,586 articles in WoS, in years $2008-2012$ (i.e. $1.77 \%$ and $1.97 \%$ of the total Spanish output). On the one hand, the evolution of TCs' documents presented a higher growth than the Spanish one $165 \%$ versus $24 \%$, Fig. 1). Nevertheless, their average number of organisations and their average number of authors were similar or lower than were those of Spain (3.29 versus 3.75 and 6.13 versus 10.76, respectively). On the other hand, considering articles and their citations, it could be observed that TCs' scientific impact was slightly higher than the average. Overall, $86 \%$ of their articles were cited, which was three points more than in the case of Spain. Furthermore, 55\% of TCs' articles were published in journals of the first quartile (Q1), compared to less than $50 \%$ of the Spanish ones.

Fig. 1 Evolution of the TCs and Spanish documents (WoS, 2008-2012)

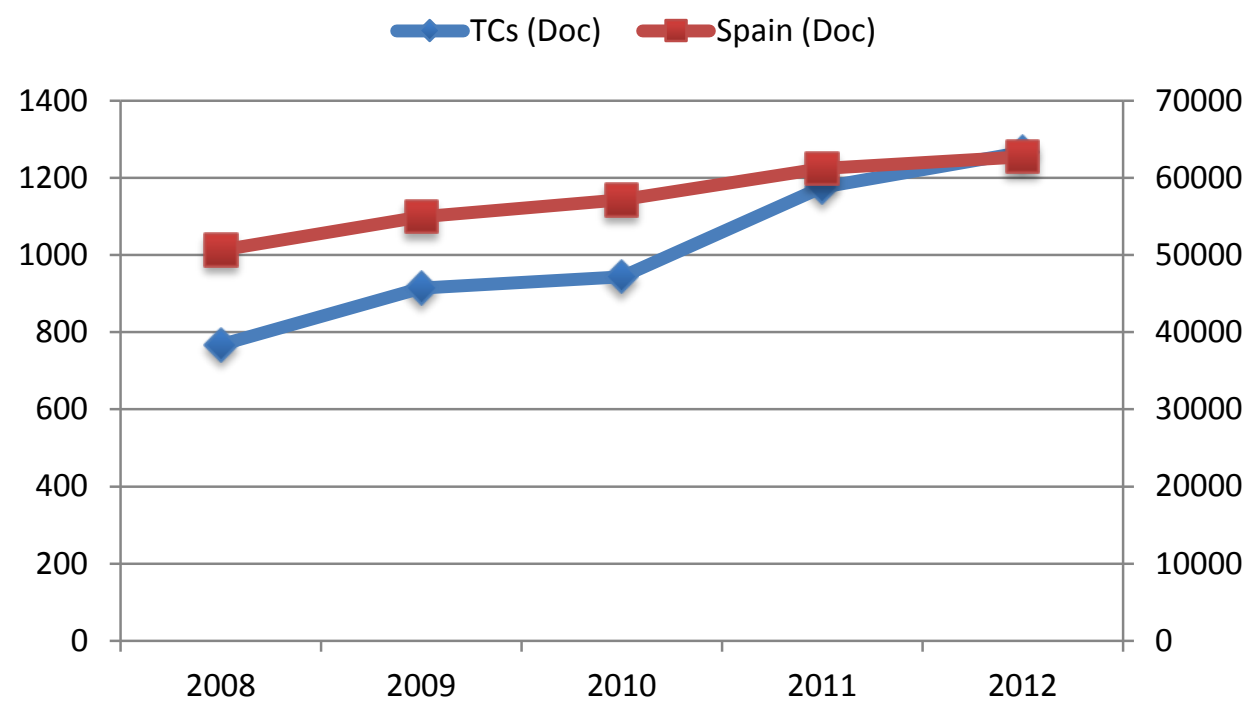

With respect to the links with other organisations, Table 1 offers the number of TCs' documents, articles and percentages without collaboration, with only national, only international, and national \& international collaboration. It also shows the average number of authors and organisations in each set of documents, the average cites per article, the percentages without citations, the average impact factor of articles and the percentage of articles in the first quartile. As in other works, collaboration implied greater impact than no collaboration. In addition, the best results for all variables were yielded by the joint national \& international collaboration, possibly explained by a higher average number of authors and 
This is a postprint version of:

Morillo, F. \& Efrain-Garcia, P. (2015). A bibliometric analysis of Technology Centres.

Scientometrics, 104(3), 685-713.

The final publication is available at Springer via http://dx.doi.org/10.1007/s11192-015-1631-5

organisations. However, the highest percentages of articles were concentrated in only national collaboration. In addition, if only national and national \& international percentages are summed, national collaboration represents as a whole almost $70 \%$ of articles $(3,190)$ or documents $(3,510)$. Furthermore, although not shown in the table, the links between local organisations (i.e. those occurring within a region) accounted for about $84 \%$ of this national collaboration, highlighting the importance of geographical proximity for TCs.

Table 1 Type of TCs' collaboration by number of documents with average number of authors/organisations and by number of articles with impact variables (WoS, 2008-2012)

\begin{tabular}{|lrrrrrrrrrr|}
\multicolumn{1}{c}{ Type } & Doc & \%Doc & Auth & Org & Art & \%Art & AvgCites & \%No Cites & AvglF & \%Q1 \\
\hline National \& international & 1067 & 21.05 & 8.40 & 5.45 & 971 & 21.17 & 11.88 & 10.50 & 3.648 & 61.07 \\
\hline Only international & 850 & 16.77 & 5.99 & 3.55 & 775 & 16.90 & 8.57 & 12.77 & 2.754 & 59.61 \\
\hline Only national & 2443 & 48.20 & 5.79 & 2.92 & 2219 & 48.39 & 7.13 & 14.83 & 2.563 & 52.55 \\
\hline Without collaboration & 708 & 13.97 & 4.04 & 1.00 & 621 & 13.54 & 6.29 & 17.71 & 2.008 & 50.40 \\
\hline Total & 5068 & 100.00 & 6.13 & 3.29 & 4586 & 100.00 & 8.26 & 13.96 & 2.750 & 55.26 \\
\hline
\end{tabular}

Doc: number of documents per type of collaboration; Auth: average number of authors in each set of documents; Org: average number of organisations in each set of documents; Art: number of articles per type of collaboration; AvgCites: average cites per article; \%No Cites: percentage of articles without citations; AvgIF: average impact factor of articles; \%Q1: percentage of articles in the first quartile.

Taking into account the high percentage of national collaboration, Table 2 offers the bonds between TCs and the Spanish institutional sectors. As it can be seen in the table, the strongest relation appeared with university, followed by the links with other non-profit organisations (NPOs), public research organisations (PROs) and the health sector. Regarding the evolution of collaboration, the greatest raise was detected in the collaboration with NPOs, followed by interactions among TCs and their ties with firms.

Table 2 TCs' collaboration with the Spanish institutional sectors (WoS documents, 2008-2012)

\begin{tabular}{|c|c|c|c|c|c|c|c|c|}
\hline Sector & 2008 & 2009 & 2010 & 2011 & 2012 & Total & $\%$ & $\Delta$ \\
\hline Administration & 20 & 14 & 22 & 27 & 34 & 117 & 3.33 & 70 \\
\hline Firms & 34 & 57 & 46 & 61 & 74 & 272 & 7.75 & 118 \\
\hline Health & 112 & 115 & 106 & 149 & 134 & 616 & 17.55 & 20 \\
\hline NPOs & 51 & 108 & 125 & 159 & 182 & 625 & 17.81 & 257 \\
\hline PROs & 87 & 98 & 124 & 165 & 149 & 623 & 17.75 & 71 \\
\hline TCs & 33 & 45 & 44 & 78 & 114 & 314 & 8.95 & 245 \\
\hline University & 350 & 403 & 441 & 583 & 600 & 2377 & 67.72 & 71 \\
\hline National collaboration & 520 & 618 & 630 & 845 & 897 & 3510 & 100.00 & 73 \\
\hline
\end{tabular}

If sectors of MINECO's register are matched to WoS categories, it is possible to know what the most important areas are, considering the number of publications. TCs included in MINECO's register published 3,651 documents (i.e. $72 \%$ of the analysed papers). These 
This is a postprint version of:

Morillo, F. \& Efrain-Garcia, P. (2015). A bibliometric analysis of Technology Centres.

Scientometrics, 104(3), 685-713.

The final publication is available at Springer via http://dx.doi.org/10.1007/s11192-015-1631-5

documents were classified by sectors and WoS categories and presented in Appendix Table 6. As it can be seen, the main subjects are related to materials science, energy and environmental sciences (for both thematic classifications). Moreover, the two last topics include the largest number of TCs.

Considering TCs' collaboration, it is important to talk about the key role of Autonomous Regions, because the regional arena is expected to be essential for industrial innovation. It should be taken into account that there is a TC, AITEMIN, which is located in four regions and has publications in Castile-La Mancha and Madrid. For this reason, it counts for both regions, although the headquarters are located in Madrid. In Table 3, different measures are shown for seventeen Spanish regions and in the studied period (2008-2012). On the one hand, with reference to the output: total number of documents of TCs \& collaborators, number of TCs, TCs' documents, their percentages and TCs' documents per TC. On the other hand, as to the regional's input indicators: average R\&D expenditure (\% of GDP), average firms' innovation intensity (innovative activities expenditure / turnover x 100), average number of firms with innovative activities per 1000 inhabitants and average R\&D university personnel per 1000 inhabitants. This last measure was also included because of the important function of University in TCs' activities (high percentage of collaboration).

As it can be noticed (Table 3 ), the first two regions accumulated more than half of the total TCs' documents (DocTC). Furthermore, with regard to the total number of documents of TCS \& collaborators (Total), the regions showed a similar trend. However, it is possible to observe some considerable exceptions, as in the case of Madrid (ranking ninth by DocTC and fourth by Total), because it had only two TCs. Nevertheless, Navarra ranked second by DocTC with only five TCs, occupying the first position by DocTC per TC (RelDocTC). Moreover, the Basque Country and Navarre had the highest values in R\&D expenditure (RD), firms' innovation intensity (Inn) and number of innovative firms (InnFirms), while Navarra also had the top number of R\&D University personnel (PersUniv). Conversely, the Canary and Balearic Islands had the lowest values in almost all measures, having no TCs and owing all their documents to national collaboration. Given the above, it appears that there may be some relationship between the regional variables and the number of TCs' documents. Therefore, and considering that not all the variables were normal, we performed a nonparametric correlation (Table 4) for the five relative variables (RelDocTC, RD, Inn, InnFirms and PersUniv) and the thirteen regions with TCs, excluding the Islands, Cantabria and La Rioja. The table show significant correlations among all variables except for PersUniv and between RD and RelDocTC. Nevertheless, PersUniv did present a significant correlation with InnFirms, 
This is a postprint version of:

Morillo, F. \& Efrain-Garcia, P. (2015). A bibliometric analysis of Technology Centres.

Scientometrics, 104(3), 685-713.

The final publication is available at Springer via http://dx.doi.org/10.1007/s11192-015-1631-5

which was the most correlated variable with RelDocTC, while RD presented high correlation with Inn and InnFirms, both correlating with RelDocTC.

Table 3 Documents and statistical measures by region (17 regions, WoS and INE databases, 2008-2012)

\begin{tabular}{|lrrrrrrrrr|}
\multicolumn{1}{c}{ Region } & Total & TCs & DocTC & \%DocTC & RelDocTC & RD & Inn & InnFirms & PersUniv \\
\hline Navarre & 1190 & 5 & 1144 & 22.6 & 228.8 & 2.03 & 1.39 & 0.904 & 3.21 \\
\hline Basque Country & 1601 & 11 & 1544 & 30.5 & 140.4 & 2.09 & 1.45 & 1.006 & 1.66 \\
\hline Aragon & 255 & 2 & 155 & 3.1 & 77.5 & 1.03 & 1.12 & 0.698 & 2.19 \\
\hline Catalonia & 1245 & 14 & 913 & 18.0 & 65.2 & 1.61 & 1.01 & 0.785 & 1.97 \\
\hline Extremadura & 144 & 2 & 128 & 2.5 & 64.0 & 0.85 & 0.50 & 0.268 & 1.17 \\
\hline Madrid & 662 & 2 & 97 & 1.9 & 48.5 & 1.98 & 1.04 & 0.634 & 2.23 \\
\hline Castile-La Mancha & 130 & 2 & 73 & 1.4 & 36.5 & 0.68 & 0.67 & 0.392 & 0.59 \\
\hline Valencia & 650 & 15 & 532 & 10.5 & 35.5 & 1.05 & 0.60 & 0.579 & 1.96 \\
\hline Castile-Leon & 285 & 7 & 201 & 4.0 & 28.7 & 1.14 & 1.29 & 0.467 & 1.88 \\
\hline Asturias & 99 & 2 & 51 & 1.0 & 25.5 & 0.98 & 0.68 & 0.411 & 1.41 \\
\hline Galicia & 241 & 7 & 166 & 3.3 & 23.7 & 0.94 & 0.98 & 0.512 & 1.77 \\
\hline Andalusia & 291 & 6 & 84 & 1.7 & 14.0 & 1.11 & 0.67 & 0.362 & 1.44 \\
\hline Murcia & 87 & 1 & 7 & 0.1 & 7.0 & 0.86 & 0.54 & 0.479 & 2.45 \\
\hline Balearic Islands & 45 & 0 & 0 & 0.0 & 0.0 & 0.37 & 0.18 & 0.380 & 0.97 \\
\hline Canary Islands & 63 & 0 & 0 & 0.0 & 0.0 & 0.59 & 0.38 & 0.372 & 1.03 \\
\hline Cantabria & 35 & 0 & 0 & 0.0 & 0.0 & 1.09 & 0.72 & 0.476 & 1.53 \\
\hline La Rioja & 6 & 0 & 0 & 0.0 & 0.0 & 1.01 & 0.96 & 0.968 & 1.38 \\
\hline
\end{tabular}

Total: total 2008-2012 documents of TCs \& collaborators by region; TCs: number of TCs in each region (2008-2012); DocTC: total 2008-2012 documents from TCs in each region; \%DocTC:

DocTC's percentage of the total documents.

Table 4 Spearman's rho Nonparametric Correlations (13 regions with TCs' documents, WoS and INE, 2008 2012)

\begin{tabular}{|l|l|rrrrr|}
\multicolumn{2}{c|}{} & RelDocTC & RD & Inn & InnFirms & PersUniv \\
\hline \multirow{2}{*}{ RelDocTC } & Correlation Coefficient & 1.000 & .505 & $.586^{*}$ & $.643^{*}$ & .209 \\
\cline { 2 - 7 } & Sig. (2-tailed) & & .078 & .035 & .018 & .494 \\
\hline \multirow{2}{*}{ RD } & Correlation Coefficient & .505 & 1.000 & $.779^{* *}$ & $.731^{* *}$ & .473 \\
\cline { 2 - 7 } & Sig. (2-tailed) & .078 & & .002 & .005 & .103 \\
\hline \multirow{2}{*}{ Inn } & Correlation Coefficient & $.586^{*}$ & $.779^{* *}$ & 1.000 & $.729^{* *}$ & .355 \\
\cline { 2 - 7 } & Sig. (2-tailed) & .035 & .002 & & .005 & .234 \\
\hline \multirow{3}{*}{ InnFirms } & Correlation Coefficient & $.643^{*}$ & $.731^{* *}$ & $.729^{* *}$ & 1.000 & $.659^{*}$ \\
\cline { 2 - 7 } & Sig. (2-tailed) & .018 & .005 & .005 & & .014 \\
\hline \multirow{2}{*}{ PersUniv } & Correlation Coefficient & .209 & .473 & .355 & $.659^{*}$ & 1.000 \\
\cline { 2 - 7 } & Sig. (2-tailed) & .494 & .103 & .234 & .014 & \\
\hline
\end{tabular}

**. Correlation is significant at the 0.01 level (2-tailed).

*. Correlation is significant at the 0.05 level (2-tailed).

ReIDocTC: total 2008-2012 documents from TCs in each region per TC; RD: regional average research and development expenditure (\% of GDP) (2008-2012); Inn: average firms' innovation intensity by region (innovative activities expenditure / turnover) x100 (2008-2012); InnFirms: average firms with innovative activities per 1000 inhabitants (2008-2012) ; PersUniv: average R\&D University personnel per 1000 inhabitants (2008-2012) 
This is a postprint version of:

Morillo, F. \& Efrain-Garcia, P. (2015). A bibliometric analysis of Technology Centres.

Scientometrics, 104(3), 685-713.

The final publication is available at Springer via http://dx.doi.org/10.1007/s11192-015-1631-5

Taking into account the relative variables of Table 4, a new statistical test was made to find groups of similar regions regarding their overall characteristics. The objective was to obtain three groups of high, medium and low performance. To this end, a k-means cluster analysis was carried out with the thirteen regions with TCs and with three variables: ReIDocTC, RD and PersUniv (the other two correlated variables were excluded). The first cluster is formed by the Basque Country and Navarre, both with high values in all variables, except for the Basque Country in PersUniv, with a value under the average. The second cluster is the biggest one, because includes seven regions: Aragon, Castile-Leon, Catalonia, Galicia, Madrid, Murcia and Valencia. It has medium values, although higher for PersUniv and lower for RelDocTC. The third cluster has four regions: Andalusia, Asturias, Castile-La Mancha and Extremadura. As those of the first cluster, these regions are quite homogeneous, offering low values in all variables, except for Extremadura in RelDocTC, with a value over the average. Fig. 2 and Fig. 3 present distributions for the three clusters and two variables: RD and InnFirms. As it can be seen, box-plots draw the highest values for the first cluster and the lowest values for the third one. Fig. 2 shows an outlier, Madrid, explained by a high percentage of R\&D investment, although with lower values for innovation.

Fig. 2 Box-plots of the percentage of R\&D expenditure of GDP for three clusters (k-means analysis)

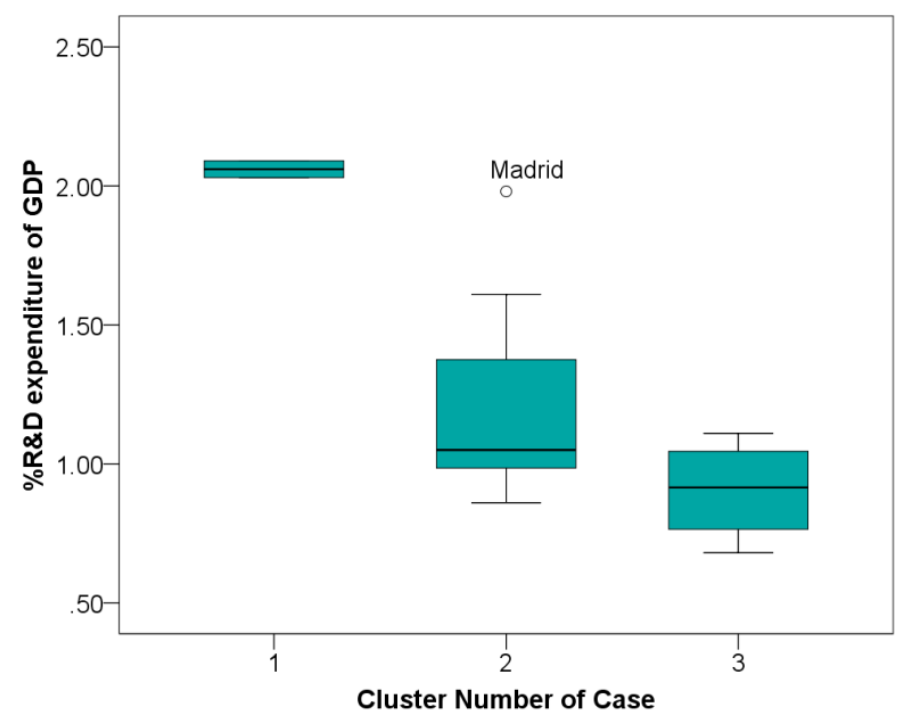


This is a postprint version of:

Morillo, F. \& Efrain-Garcia, P. (2015). A bibliometric analysis of Technology Centres.

Scientometrics, 104(3), 685-713.

The final publication is available at Springer via http://dx.doi.org/10.1007/s11192-015-1631-5

Fig. 3 Box-plots of firms with innovative activities per 1000 inhabitants for three clusters (k-means analysis)

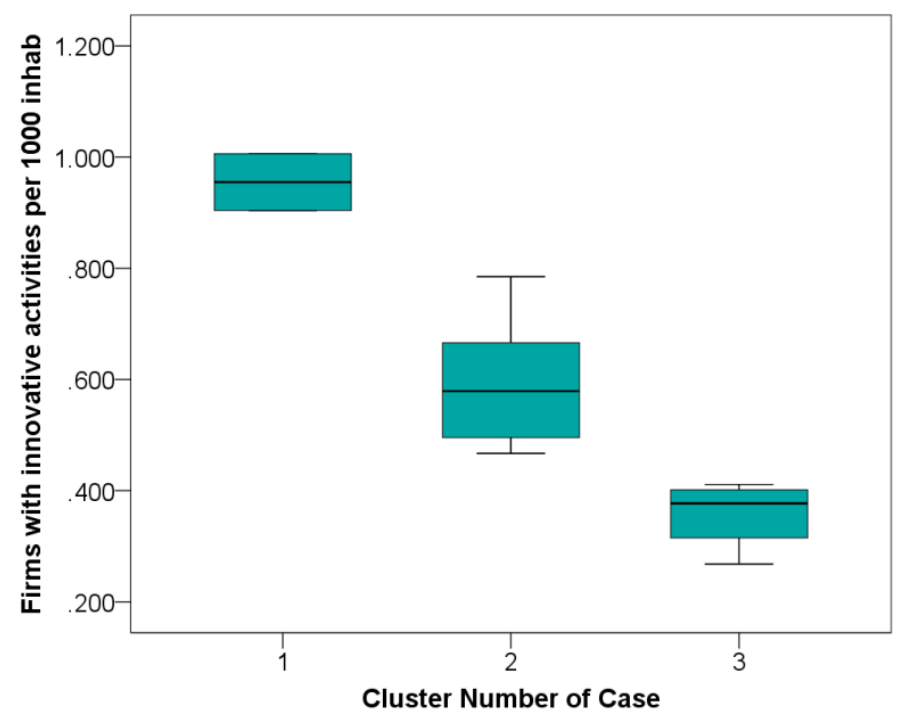

When studying all the regional interactions and the total number of documents of TCs \& collaborators, it could be observed that those with a better performance boosted the others production (Fig. 4). Madrid, even with just two low productive TCs, presented a great deal of national collaboration (89\%), due to documents jointly published by its non-Technology organisations and TCs from other regions. Besides, the four regions with the highest production, in documents of TCs \& collaborators, draw on the map triangles of strong links. However, for regions without TCs, cooperation was even more important as they needed to connect all their documents in national collaboration if they wanted to reach TCs in other regions (La Rioja, Cantabria and the Islands). Moreover, these regions also had varied connections, considering the different links between geographical areas, and most of these relationships were multilateral, including organisations from three or more regions (Fig. 4). Some of them cooperated with their neighbours and others chose other associations because they were top producers, no matter how far they were (the Balearic and Canary Islands). In this sense, the Balearic Islands presented $42 \%$ of collaboration with the Basque Country, although with Catalonia, geographically closer to them, they had $40 \%$ of documents in common. Regarding the Canary Islands, they connected in $37 \%$ of their publications with Navarre, far away from them, and had $29 \%$ of cooperation with Castile-La Mancha, located a little closer. As far as Cantabria and La Rioja are concerned, nearby relations were preferred. In the case of Cantabria, $63 \%$ of its documents were signed with the Basque Country, while La Rioja had $83 \%$ of links with Navarre. With respect to the Spanish institutional sectors involved in these collaborations, the university sector was the most participative (although in less than half of the documents), followed by PROs (19\%) and other public related sectors. 
This is a postprint version of:

Morillo, F. \& Efrain-Garcia, P. (2015). A bibliometric analysis of Technology Centres.

Scientometrics, 104(3), 685-713.

The final publication is available at Springer via http://dx.doi.org/10.1007/s11192-015-1631-5

In addition, a few firms, established mainly in the Islands, signed some of these publications. Finally, the main disciplines of publication were related to engineering (particularly energy and materials), medicine (neurosciences) and environmental topics.

Fig. 4 Network of collaboration among 17 Spanish regions with Pajek (WoS, 2008-2012) and number of TCs by region represented in a colour scale (a darker colour means a higher number of centres)

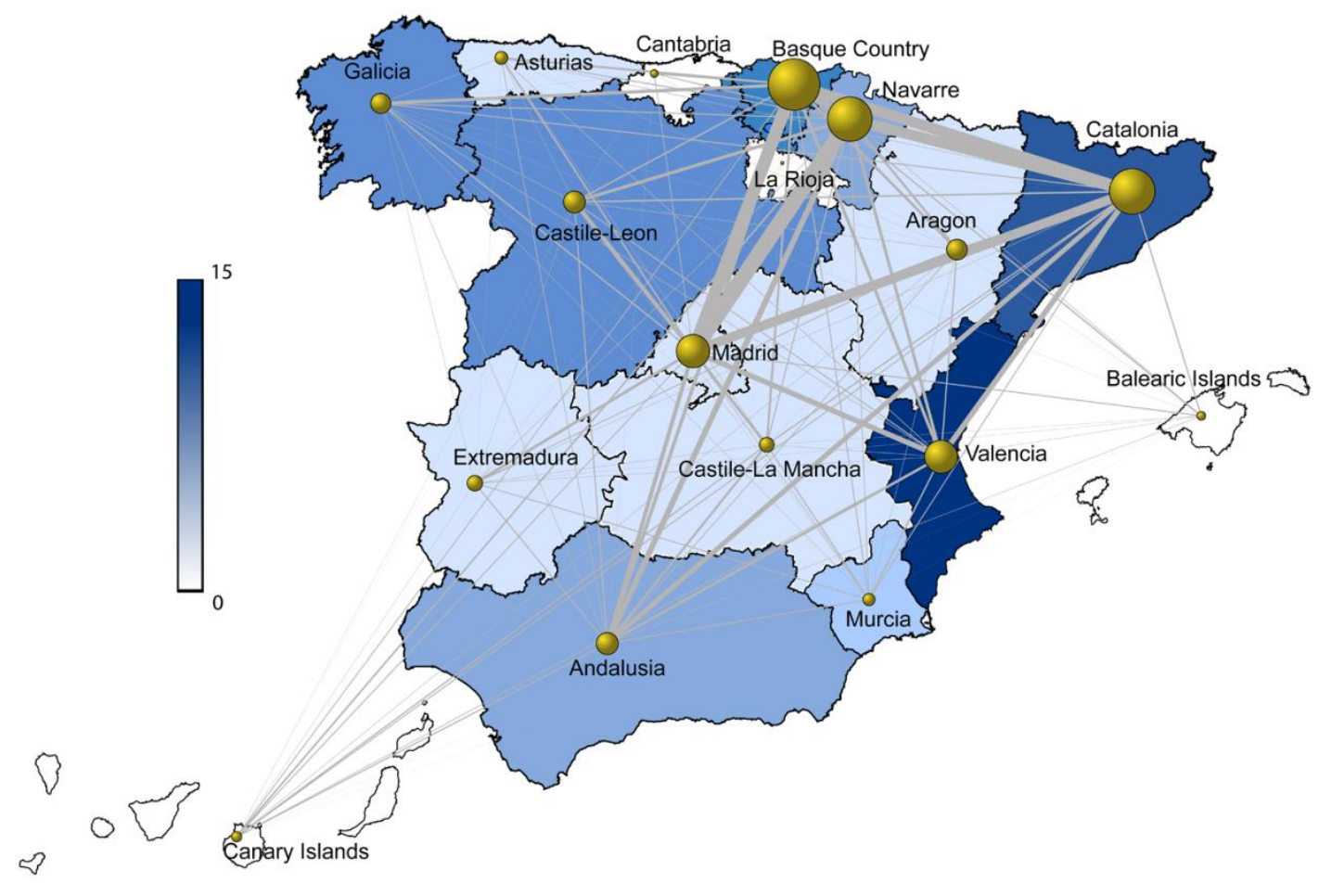

\section{Discussion and conclusions}

This study describes the importance of TCs as creators of scientific output, increasingly connecting public and private sectors. The general results showed that these centres produced less than $2 \%$ of the total Spanish publications, but their growth throughout the period was much greater than the Spanish one and their scientific impact was also slightly higher. Likewise, TCs' collaboration was much higher than the Spanish one and the national links even more, as predicted in the first hypothesis. The latter is quite logical, considering that TCs need to cooperate with different agents to provide a quick and effective service. Moreover, a great deal of the national connections included collaboration between local organisations, which is in line with other studies. For instance, the case offered by BavieraPuig et al. (2012) shows a high local cooperation, since geographical proximity is important for knowledge transfer. However, these authors also point out that TCs can meet the needs 
This is a postprint version of:

Morillo, F. \& Efrain-Garcia, P. (2015). A bibliometric analysis of Technology Centres.

Scientometrics, 104(3), 685-713.

The final publication is available at Springer via http://dx.doi.org/10.1007/s11192-015-1631-5

of remote firms, provided they are properly connected. Therefore, this probably explains those connections between distant regions on the map.

On the subject of the Spanish institutional sectors, the strongest relations appeared with public organisations, mainly with university. Furthermore, there were great growths in the cooperation with NPOs, TCs and, surprisingly, with firms, which is an indication that these last seem to give increased importance to scientific publication. The high proportion of documents in national collaboration with University could be explained by the strong links between many TCs and some university departments, which was stated in the first hypothesis. Moreover, most publications between TCs and firms were also produced by the public sector, making it possible to see how TCs can encourage knowledge transfer between both sectors. This was studied preliminarily in the work of Morillo et al. (2014), whose findings foresee the importance of intermediaries to facilitate knowledge transfer. Besides, the largest number of TCs and their main publications were related to industry (i.e. engineering and technological areas), proving that support for firms' innovation by TCs has an effect on their choice of research topics.

In addition, some parallelisms with other studies were observed, concerning differences among TCs, which were partly due to the characteristics of their regional innovation systems (e.g. Barge-Gil and Modrego-Rico 2008). In this work, the increase in R\&D expenditure was associated with the growth in the number of firms with innovative activities and in firms' innovation intensity. Moreover, those regions with higher innovation values also showed greater relative TCs' scientific output and offered important connections for smaller regions. This confirms the second hypothesis of differences between regions explained in part by disparities in regional development. That is, firms with innovative activities take advantage from TCs' technological support that, in turn, depend on their respective regional RTD systems, which play an important role in the promotion of competitiveness.

In the study by Gómez et al. (2005), the most technologically advanced regions are Navarra, the Basque Country and Catalonia and at the other extreme are the Balearic and Canary Islands. Besides, the authors state that Madrid is the strongest region from the scientific point of view, while only a small percentage of its population works in the industrial sector. Similarly, in our work, we could observe that Navarra and the Basque Country occupied the first positions by relative TCs' scientific production, forming the first cluster of our study (the high performance group). Moreover, the Balearic and Canary Islands also had very low values in the input indicators, having no TCs. Additionally, Madrid (that belongs to the 
This is a postprint version of:

Morillo, F. \& Efrain-Garcia, P. (2015). A bibliometric analysis of Technology Centres.

Scientometrics, 104(3), 685-713.

The final publication is available at Springer via http://dx.doi.org/10.1007/s11192-015-1631-5

medium performance group) occupied the third position by R\&D expenditure, but it only had two TCs and medium values in TCs' documents and in innovation variables. Nevertheless, it showed strong connections with the top producers, ranking fourth by total number of documents of TCs \& collaborators. Regarding regions without TCs (La Rioja, Cantabria and the Islands), they produced some documents in collaboration, mainly signed by three or more organisations. Besides, the university sector was the most participative, establishing the majority of its relations with TCs from the Basque Country and Navarre in engineering, medicine and environmental topics.

In conclusion, it can be said that the bibliometric point of view provides useful information to assess TCs' performance and their compliance with the objectives for which they were created. Likewise, it can be stated that RTD regional systems have an important role and a relevant impact on the overall economic development. Further research may offer the firms' perspective and see how TCs may help them in improving their competitiveness.

\section{Acknowledgements}

This work is supported by the Spanish Ministry of Science and Innovation (Grant CSO2011-25102). We want to thank Borja González-Albo and Luz Moreno for their valuable collaboration in the identification of TCs and Adrián A. Díaz-Faes for his suggestions about statistics methodology.

\section{Appendix}

Table 5 Technology Centres included in this study (with documents in WoS, 2008-2012)

\begin{tabular}{|c|c|}
\hline Technology Centres $\&$ their locations & $\begin{array}{l}\text { In MINECO's } \\
\text { register }\end{array}$ \\
\hline AIMEN, Pontevedra (Galicia) & Yes \\
\hline AITEMIN, Madrid \& Toledo (Madrid \& Castile-La Mancha) & Yes \\
\hline Asoc.Ind.Navarra (AIN) (Navarre) & Yes \\
\hline \multicolumn{2}{|l|}{ Asoc.Inv.Ind.Curtido Anexas, Barcelona (Catalonia) } \\
\hline \multicolumn{2}{|l|}{ Asoc.Prov.Emp.Cosech-Exp.Prd.Hort. Almería (Andalusia) } \\
\hline Azterlan, Vizcaya (Basque Country) & Yes \\
\hline Barcelona Media, Barcelona (Catalonia) & Yes \\
\hline C.And.Innov.Tecnol.Inf.Comun., Málaga (Andalusia) & Yes \\
\hline C.Avanz.Tecnol.Aeroespacial, Sevilla (Andalusia) & Yes \\
\hline \multicolumn{2}{|l|}{ C.Cirugía Mínima Invasión, Cáceres (Extremadura) } \\
\hline \multicolumn{2}{|l|}{ C.Desarr.Telecomunic., Valladolid (Castile-Leon) } \\
\hline C.Est.Inv.Técn., Guipúzcoa (Basque Country) & Yes \\
\hline
\end{tabular}


This is a postprint version of:

Morillo, F. \& Efrain-Garcia, P. (2015). A bibliometric analysis of Technology Centres.

Scientometrics, 104(3), 685-713.

The final publication is available at Springer via http://dx.doi.org/10.1007/s11192-015-1631-5

\begin{tabular}{|c|c|}
\hline Technology Centres \& their locations & $\begin{array}{l}\text { In MINECO's } \\
\text { register }\end{array}$ \\
\hline \multicolumn{2}{|l|}{ C.Inv.Innov.Toxicol., UPC, Barcelona (Catalonia) } \\
\hline C.Inv.Med. Aplic., UNAV (Navarre) & Yes \\
\hline \multicolumn{2}{|l|}{ C.Nac.Energ.Renov., (Navarre) } \\
\hline C.Nac.Tecnol.Seg.Alim., (Navarre) & Yes \\
\hline \multicolumn{2}{|l|}{ C.Nuevas Tecnol.Agua, Sevilla (Andalusia) } \\
\hline \multicolumn{2}{|l|}{ C.Tecnol. Azucarera CTA, UVa, Valladolid (Castile-Leon) } \\
\hline C.Tecnol.Agr.Agroalim., Palencia (Castile-Leon) & Yes \\
\hline \multicolumn{2}{|l|}{ C.Tecnol.Bioméd., UPM, (Madrid) } \\
\hline \multicolumn{2}{|l|}{ C.Tecnol.Carne, Galicia (Ourense) } \\
\hline \multicolumn{2}{|l|}{ C.Tecnol.Forest.Madera, (Asturias) } \\
\hline \multicolumn{2}{|l|}{ C.Tecnol.Forestal de Cataluña, Lleida (Catalonia) } \\
\hline \multicolumn{2}{|l|}{ C.Tecnol.Gallego Acuicultura, A Coruña (Galicia) } \\
\hline \multicolumn{2}{|l|}{ C.Tecnol.Manresa, Catalonia (Barcelona) } \\
\hline \multicolumn{2}{|l|}{ C.Tecnol.Mar-Fund.CETMAR, Galicia (Pontevedra) } \\
\hline C.Tecnol.Nac.Conserva Alimentación, (Murcia) & Yes \\
\hline \multicolumn{2}{|l|}{ C.Tecnol.Nutr.Salud, Tarragona (Catalonia) } \\
\hline \multicolumn{2}{|l|}{ C.Tecnol.Telecomun.Cat., Barcelona (Catalonia) } \\
\hline \multicolumn{2}{|l|}{ C.Tecnol.Vilanova Geltrú, UPC, Barcelona (Catalonia) } \\
\hline CARTIF, Valladolid (Castile-Leon) & Yes \\
\hline Cecopesca, Anfaco, Pontevedra (Galicia) & Yes \\
\hline CEMITEC, (Navarre) & Yes \\
\hline \multicolumn{2}{|l|}{ Cetaqua, Barcelona (Catalonia) } \\
\hline CETEMMSA, Barcelona (Catalonia) & Yes \\
\hline \multicolumn{2}{|l|}{ CICAP, Córdoba (Andalusia) } \\
\hline CIDETEC, Guipúzcoa (Basque Country) & Yes \\
\hline \multicolumn{2}{|l|}{ CIS Madera, Ourense (Galicia) } \\
\hline \multicolumn{2}{|l|}{ CIT UPC, Barcelona (Catalonia) } \\
\hline \multicolumn{2}{|l|}{ Est.Exp.Las Palmerillas, Almería (Andalusia) } \\
\hline Fund.Ascamm, Barcelona (Catalonia) & Yes \\
\hline Fund.C.Tecnol.Aeron., Álava (Basque Country) & Yes \\
\hline Fund.CIDAUT, Valladolid (Castile-Leon) & Yes \\
\hline Fund.CIRCE, Zaragoza (Aragon) & Yes \\
\hline Fund.Gaiker, Vizcaya (Basque Country) & Yes \\
\hline Fund.I.Tecnol.Materiales, (Asturias) & Yes \\
\hline Fund.Tekniker, Guipúzcoa (Basque Country) & Yes \\
\hline Gradiant, Pontevedra (Galicia) & Yes \\
\hline I.Biomecánica, UPV, (Valencia) & Yes \\
\hline \multicolumn{2}{|l|}{ I.Biotecnol., ULe, León (Castile-Leon) } \\
\hline \multicolumn{2}{|l|}{ I.Inv.Energ.Renov.,UCLM, Albacete (Castile-La Mancha) } \\
\hline \multicolumn{2}{|l|}{ I.Inv.Textil Coop.Ind, UPC, Barcelona (Catalonia) } \\
\hline I.ITACA, UPV, (Valencia) & Yes \\
\hline I.Tecnol.Agroalim. (AINIA), (Valencia) & Yes \\
\hline \multicolumn{2}{|l|}{ I.Tecnol.Agroalim., Badajoz (Extremadura) } \\
\hline \multicolumn{2}{|l|}{ I.Tecnol.Aragón, Zaragoza (Aragon) } \\
\hline I.Tecnol.Calzado Conexas, Alacant (Valencia) & Yes \\
\hline I.Tecnol.Cerám., UJI, Castelló (Valencia) & Yes \\
\hline
\end{tabular}


This is a postprint version of:

Morillo, F. \& Efrain-Garcia, P. (2015). A bibliometric analysis of Technology Centres.

Scientometrics, 104(3), 685-713.

The final publication is available at Springer via http://dx.doi.org/10.1007/s11192-015-1631-5

\begin{tabular}{|lc|}
\multicolumn{1}{|c|}{ Technology Centres \& their locations } & $\begin{array}{c}\text { In MINECO's } \\
\text { register }\end{array}$ \\
\hline I.Tecnol.Construcción (AIDICO), (Valencia) & Yes \\
\hline I.Tecnol.Eléctrica, (Valencia) & Yes \\
\hline I.Tecnol.Embalaje,Transp.Logística, (Valencia) & Yes \\
\hline I.Tecnol.Informát., UPV, (Valencia) & Yes \\
\hline I.Tecnol.Juguete, Alacant (Valencia) & Yes \\
\hline I.Tecnol.Ópt.Color Imagen, (Valencia) & Yes \\
\hline I.Tecnol.Plástico (AIMPLAS), (Valencia) & Yes \\
\hline I.Tecnol.Textil, Alacant (Valencia) & Yes \\
\hline I.Toxicol., ULe, León (Castile-Leon) & \\
\hline Ideko, Guipúzcoa (Basque Country) & Yes \\
\hline Ikerlan S.Coop., Álava \& Guipúzcoa (Basque Country) & Yes \\
\hline Inst.Tecnol.Metalmecánico, (Valencia) & Yes \\
\hline Inst.Tecnol.Mueble, Madera, Embalaje Afines, (Valencia) & Yes \\
\hline Leitat, Barcelona (Catalonia) & Yes \\
\hline Lortek, Basque Country (Guipúzcoa) & Yes \\
\hline Tecnalia, Álava, Guipúzcoa \& Vizcaya (Basque Country) & Yes \\
\hline Vicomtech-IK4, Guipúzcoa (Basque Country) & Yes \\
\hline
\end{tabular}




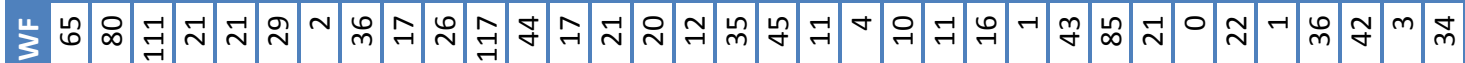

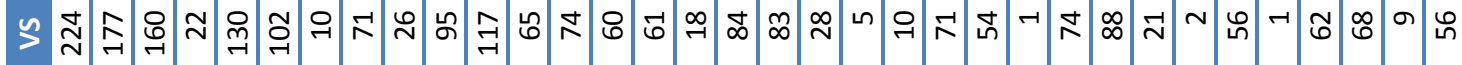

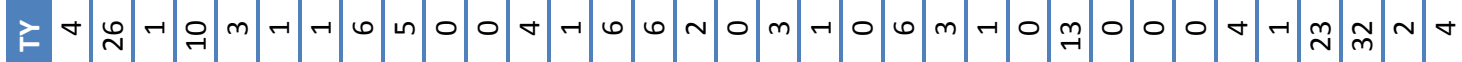

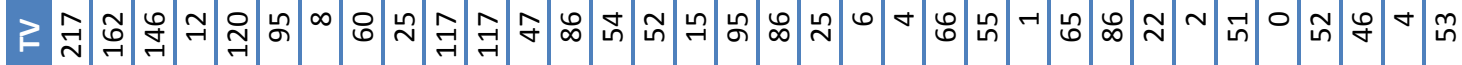

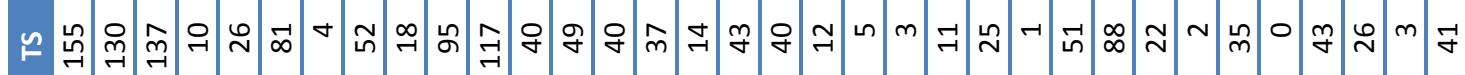

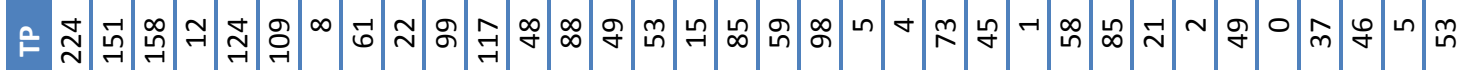

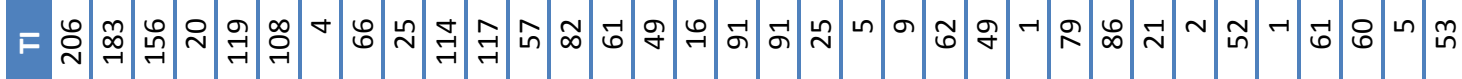

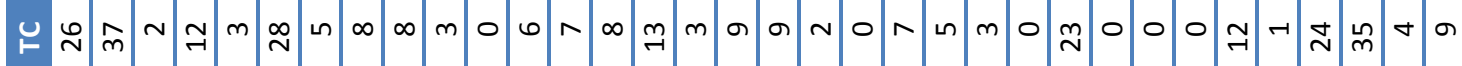

$\vdash \infty$

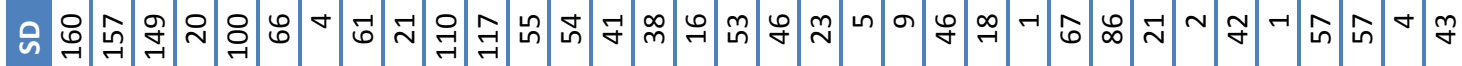

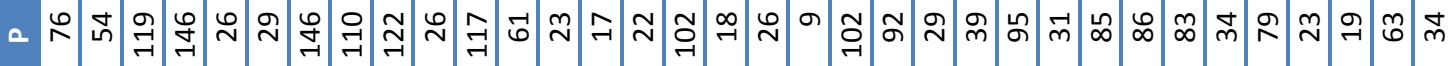

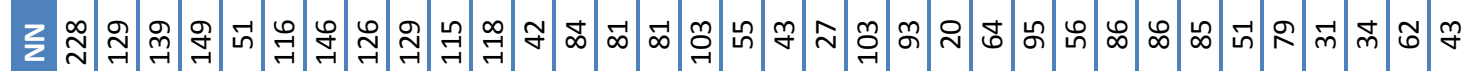

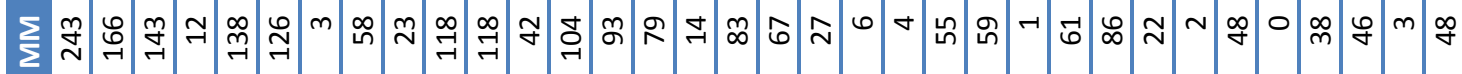

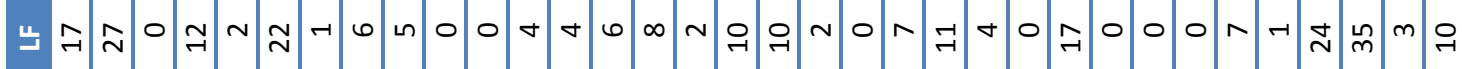

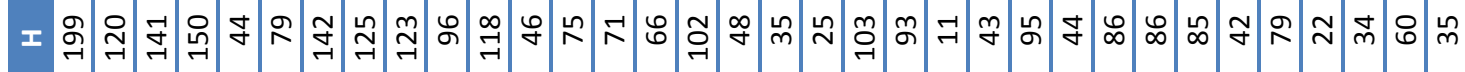

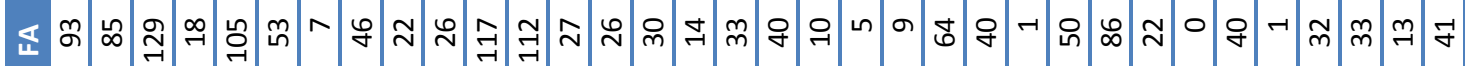

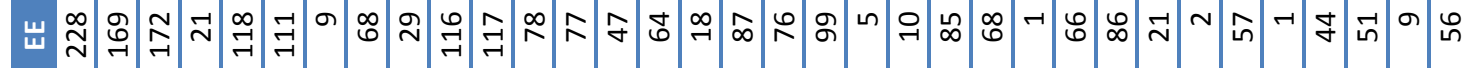

ب

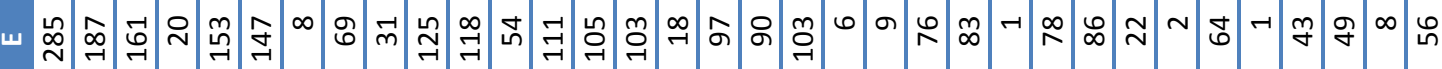

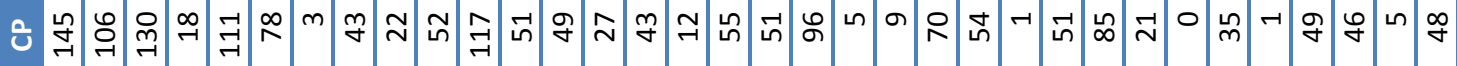

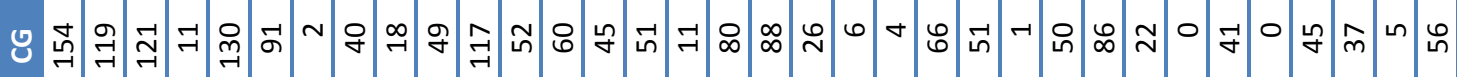

৩ ڤ્ન

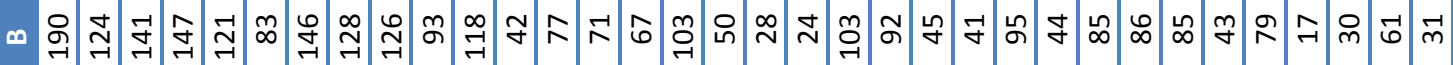

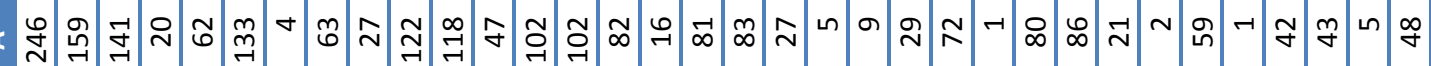



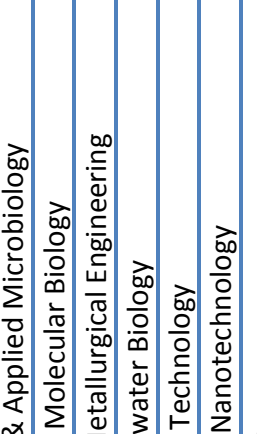

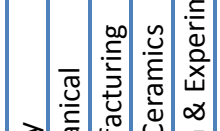

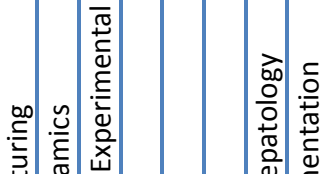

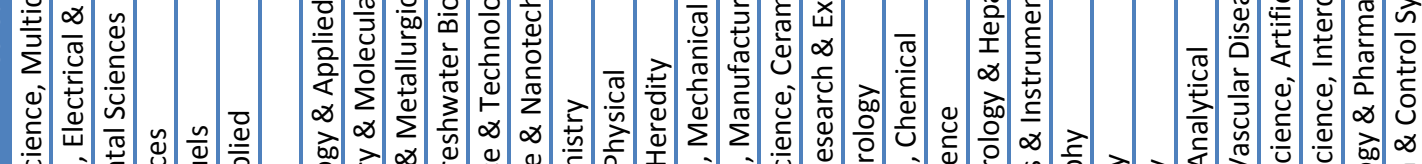

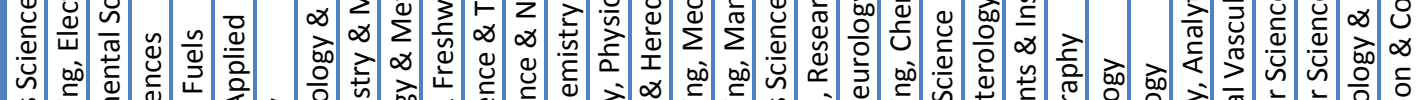

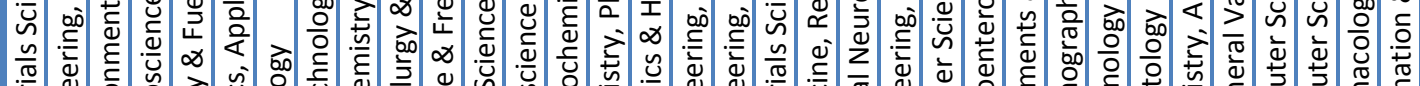

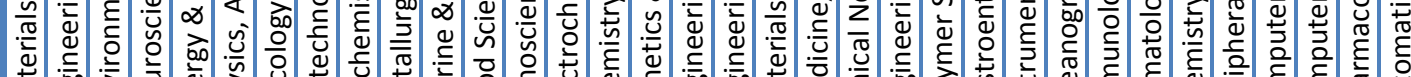




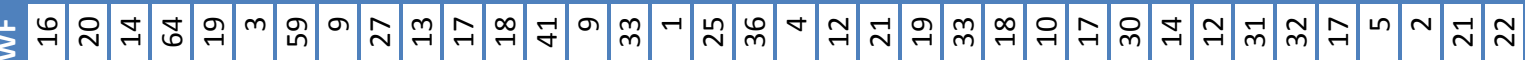
ร๐ิ

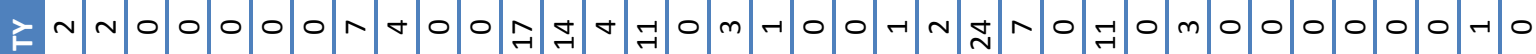

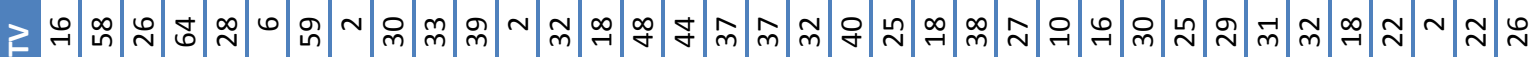

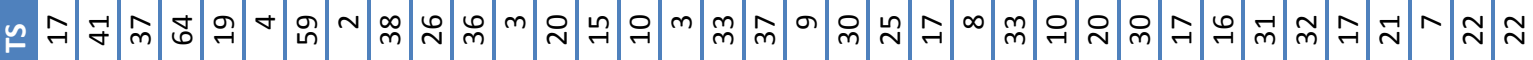

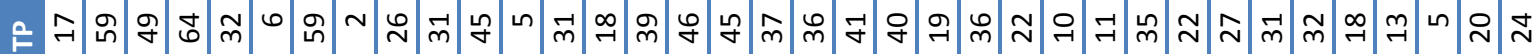

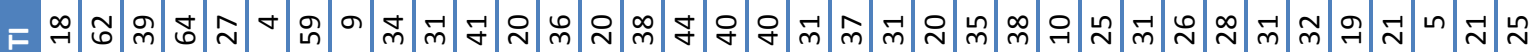

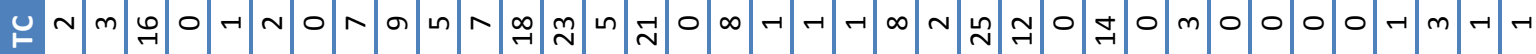
- $A$ J ம)

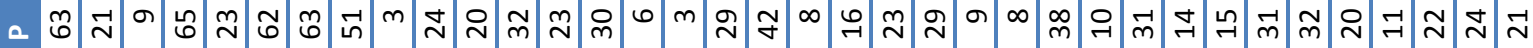

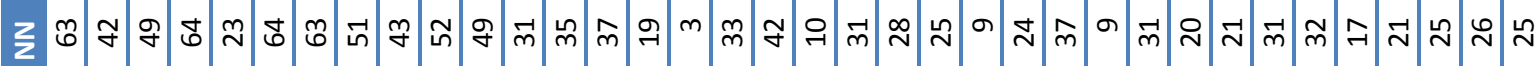

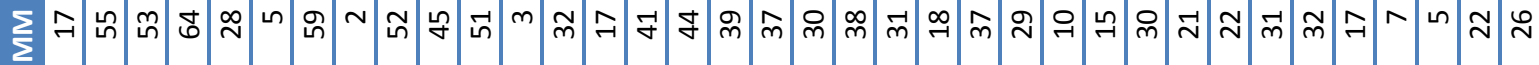

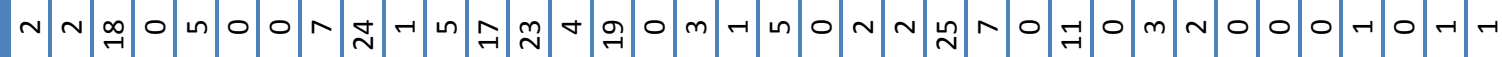
I «ㄱㄱำ సิ

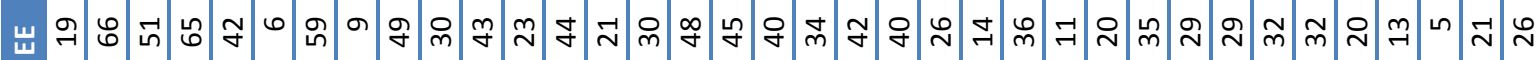

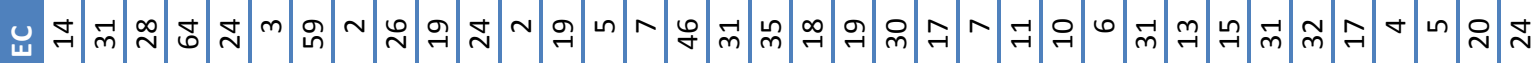

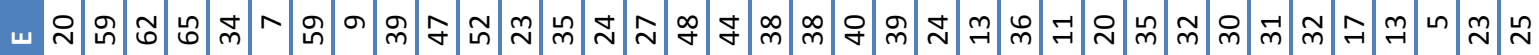

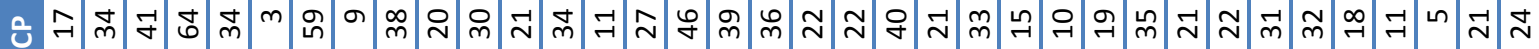

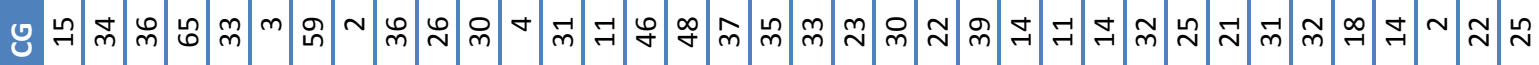

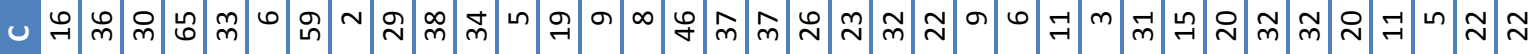

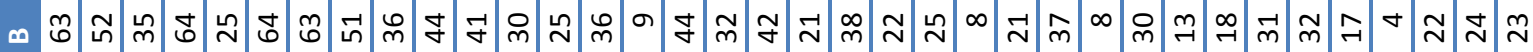

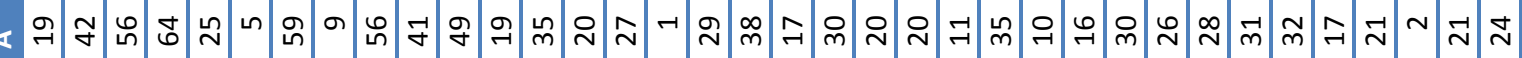

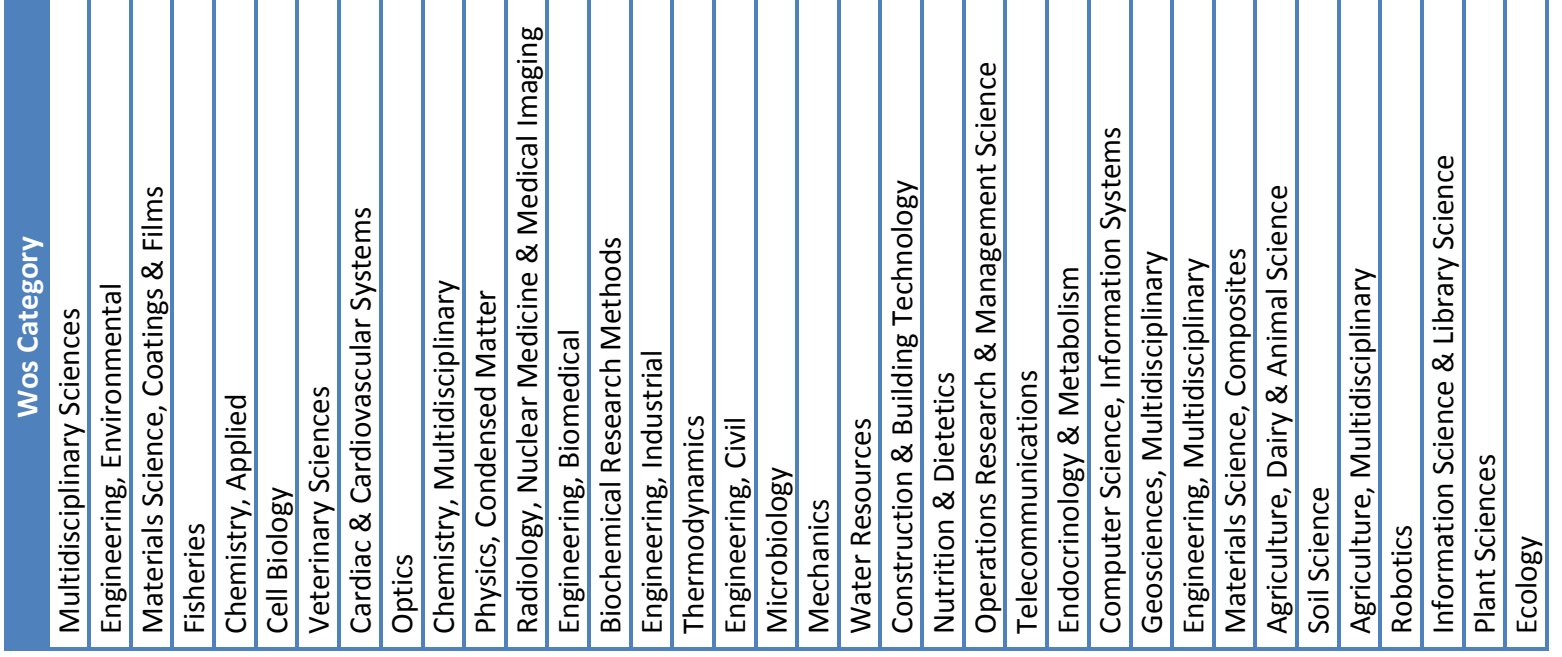


䓠 우

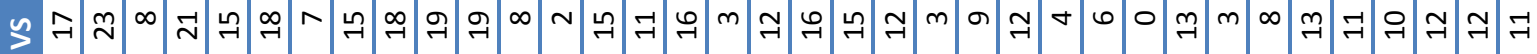

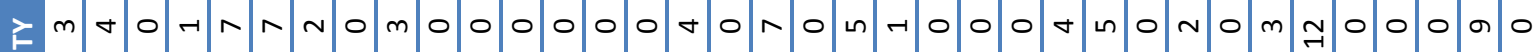

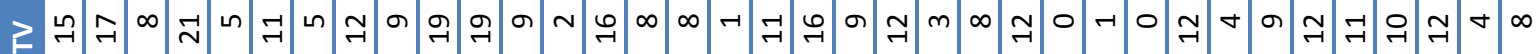

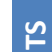

음 의

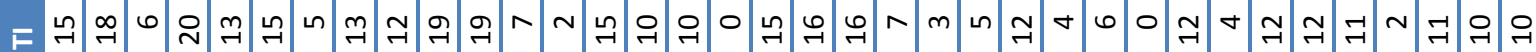

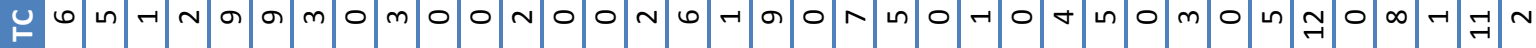

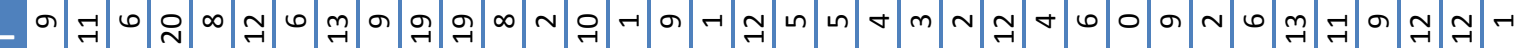
윽의

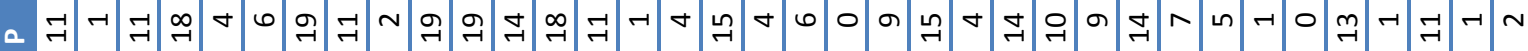
란

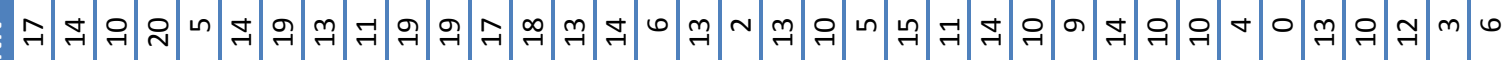

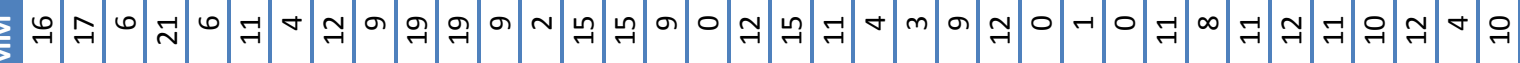

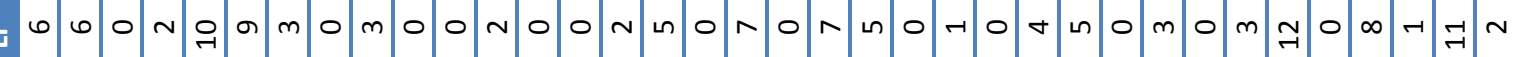

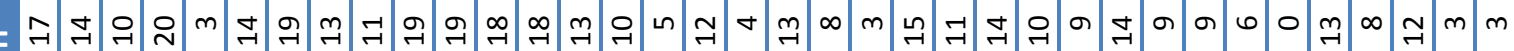

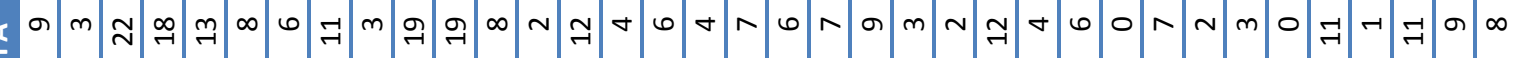
แ ư

山

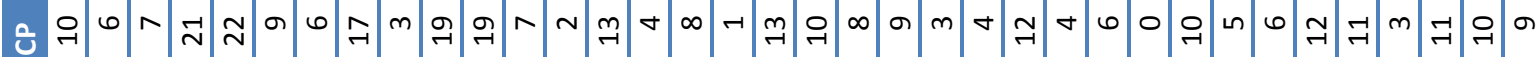

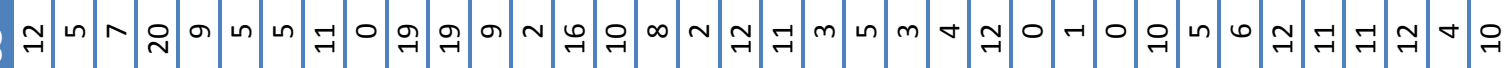

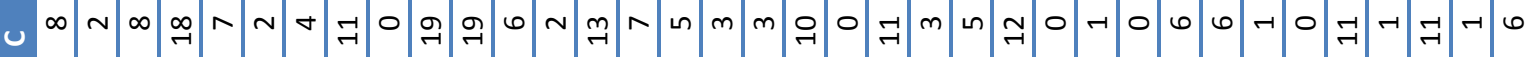

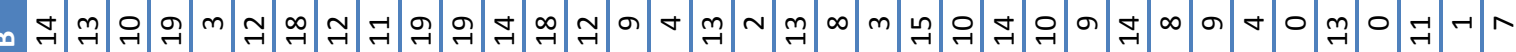
《 $ન$ అ

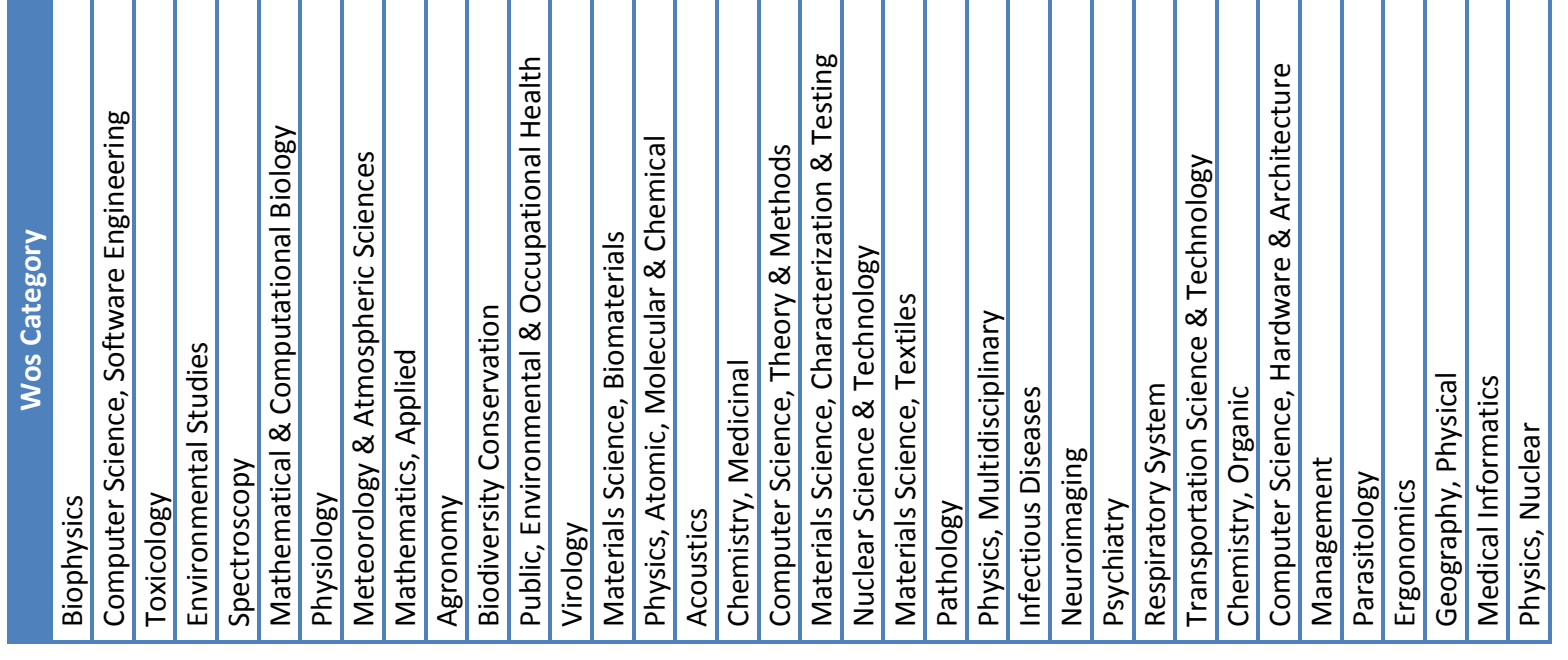




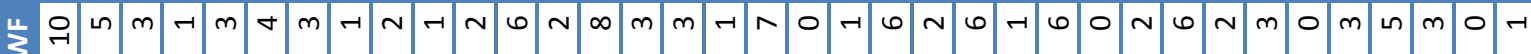

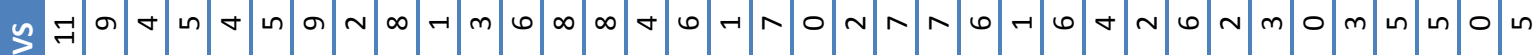

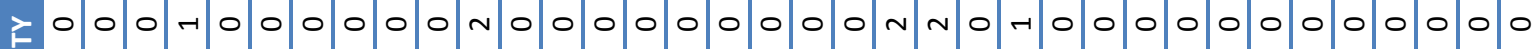
$\geq$

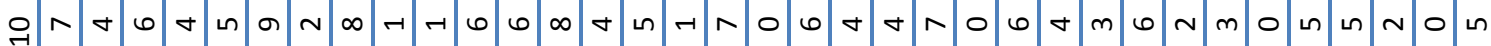

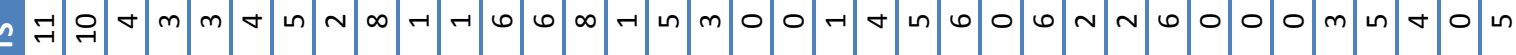

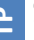

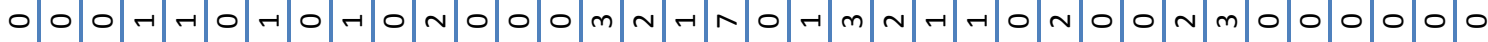

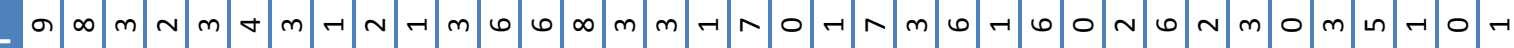
只

a

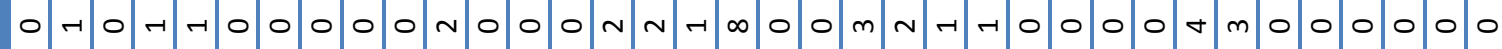

I 딴

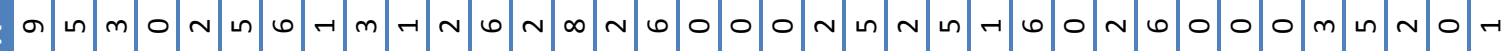

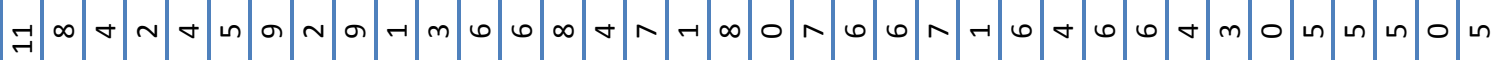

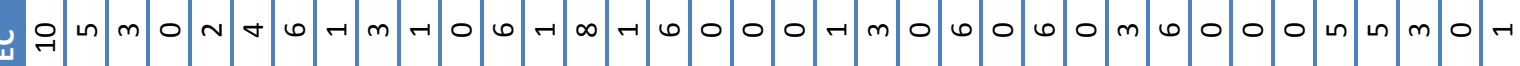
m

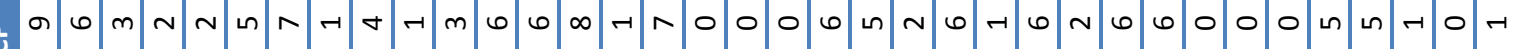
ర

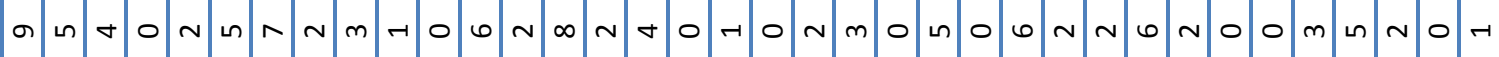
m 욱 $\infty$ 어

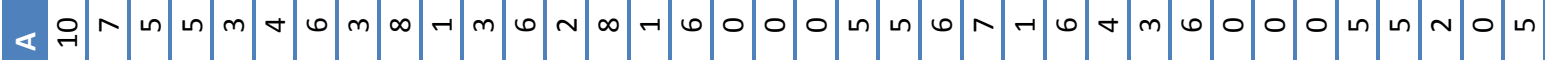

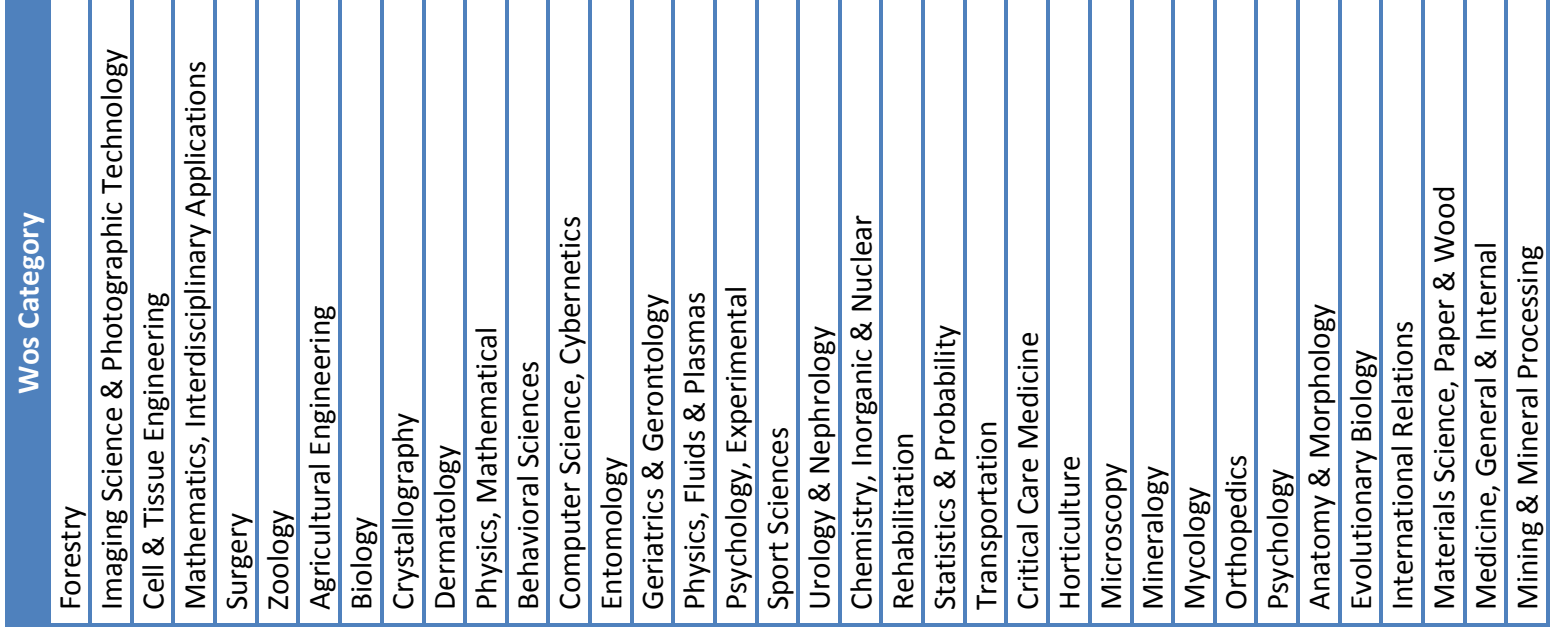




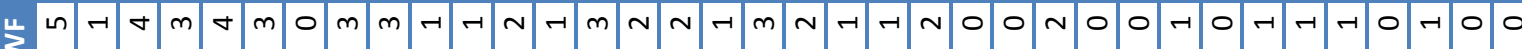

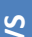

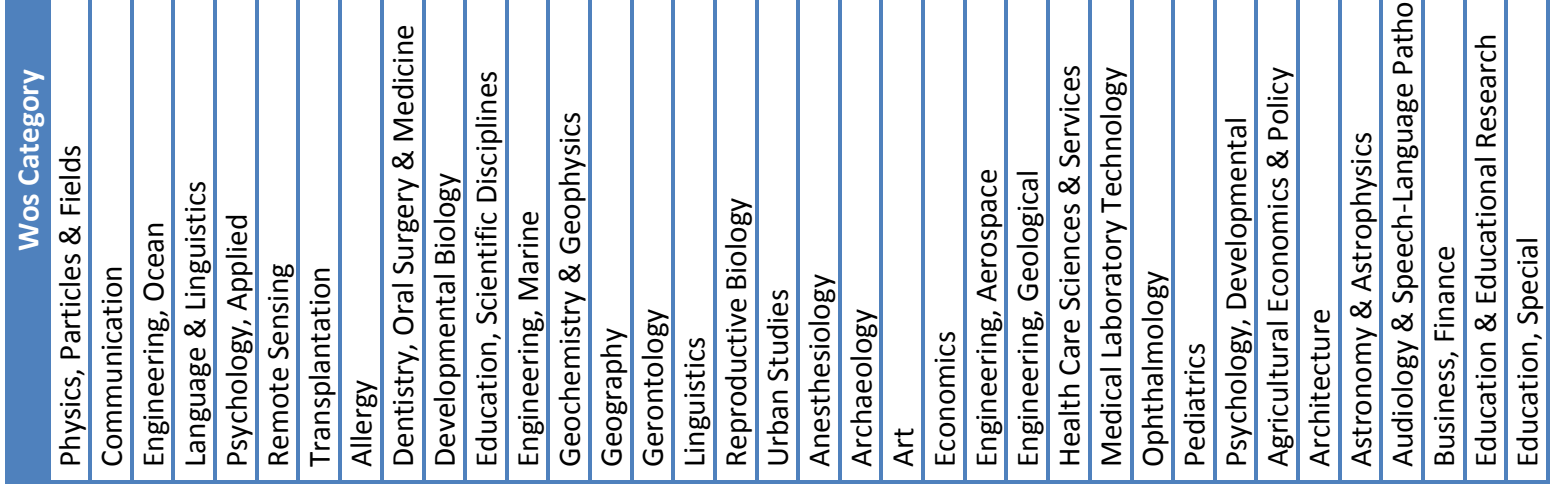




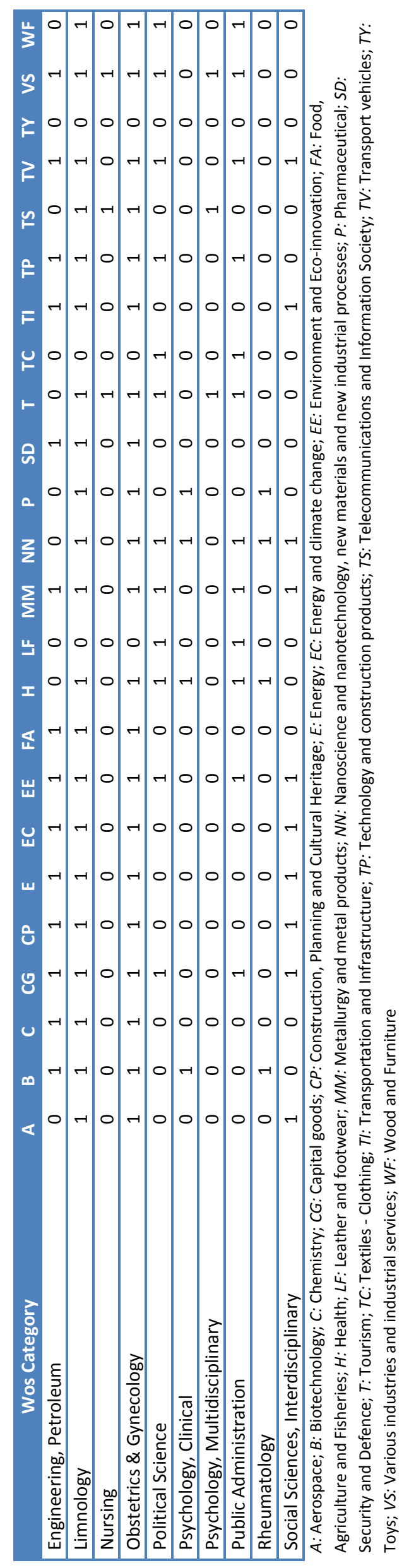




\section{References}

Ahlqvist, T., Halonen, M., Eerola, A., Kivisaari, S., Kohl, J., Koivisto, R., Myllyoja, J., \& Wessberg, N. (2012). Systemic transformation, anticipatory culture, and knowledge spaces: constructing organisational capacities in roadmapping projects at VTT Technical Research Centre of Finland. Technology Analysis \& Strategic Management, 24(8), 821-841. doi:10.1080/09537325.2012.715490

Barge-Gil, A., \& Modrego, A. (2011). The impact of research and technology organizations on firm competitiveness. Measurement and determinants. The Journal of Technology Transfer, 36(1), 6183. doi:10.1007/s10961-009-9132-4

Barge-Gil, A., \& Modrego-Rico, A. (2008). Are technology institutes a satisfactory tool for public intervention in the area of technology? A neoclassical and evolutionary evaluation. Environment and Planning C: Government and Policy, 26(4), 808-823. doi:10.1068/c70m

Batagelj, V., \& Mrvar, A. (2013). Pajek - Program for Large Network Analysis. Retrieved from http://vlado.fmf.uni-lj.si/pub/networks/pajek/. Accessed 28 May 2015.

Baviera-Puig, A., Buitrago-Vera, J., \& Mas-Verdú, F. (2012). Trade areas and knowledge-intensive services: the case of a technology centre. Management Decision, 50(8), 1412-1424. doi:10.1108/00251741211262006

Giner, J., \& Santa María, M. J. (2000). La política de centros tecnológicos y de servicios: la experiencia de las regiones valenciana y Emilia-Romagna. Revista de estudios regionales, 57, 131-149.

Gómez, I., Bordons, M., Morillo, F., \& Fernández, M. T. (2005). Regionalisation of science and technology data in Spain. Research evaluation, 14(2), 137-148. doi:10.3152/147154405781776193

IBM Corp. (Released 2013). IBM SPSS Statistics for Windows. Version 22.0. Armonk, NY: IBM Corp.

Mas-Verdú, F. (2007). Services and innovation systems: European models of Technology Centres. Service Business, 1(1), 7-23. doi:10.1007/s11628-006-0002-y

Modrego-Rico, A., Barge-Gil, A., \& Núñez-Sánchez, R. (2005)._Developing indicators to measure technology institutes' performance. Research Evaluation, 14(2), 177-184. doi:10.3152/147154405781776229

Morillo, F., Aparicio, A., González-Albo, B., \& Moreno, L. (2013a). Towards the automation of addresses identification. Scientometrics, 94(1), 207-224. doi:10.1007/s11192-012-0733-6

Morillo, F., González-Albo, B., \& Moreno, L. (2014). Public-private co-publications beyond universityindustry links. In Proceedings of STI 2014 Leiden. Retrieved from http://sti2014.cwts.nl/download/f-y2w2.pdf. Accessed 28 May 2015. 
Morillo, F., Santabárbara, I., \& Aparicio, J. (2013b). The automatic normalisation challenge: Detailed addresses identification. Scientometrics, 95(3), 953-966. doi:10.1007/s11192-013-0965-0

Schramm, L.L., Nyirfa, W., Grismer, K., \& Kramers, J. (2011). Research and development impact assessment for innovation-enabling organizations. Canadian public administration, 54(4), 567581. doi:10.1111/j.1754-7121.2011.00193.x 